\title{
Chloride Transport of High Alumina Cement Mortar Exposed to a Saline Solution
}

\author{
Hee Jun Yang, Sung Ho Jin, and Ki Yong Ann \\ Department of Civil and Environmental Engineering, Hanyang University, Ansan 15588, Republic of Korea \\ Correspondence should be addressed to Ki Yong Ann; kann@hanyang.ac.kr
}

Received 7 October 2016; Accepted 6 December 2016

Academic Editor: Paulo H. R. Borges

Copyright (C) 2016 Hee Jun Yang et al. This is an open access article distributed under the Creative Commons Attribution License, which permits unrestricted use, distribution, and reproduction in any medium, provided the original work is properly cited.

Chloride transport in different types of high alumina cement (HAC) mortar was investigated in this study. Three HAC cement types were used, ranging from 52.0 to $81.1 \%$ of aluminum oxides in clinker. For the development of the strength, the setting time of fresh mortar was measured immediately after mixing and the mortar compressive strength was cured in a wet chamber at $25 \pm 2{ }^{\circ} \mathrm{C}$ and then measured at 1-91 days. Simultaneously, to assess the rate of chloride transport in terms of diffusivity, the chloride profile was performed by an exposure test in this study, which was supported by further experimentation including an examination of the pore structure, chloride binding, and chemical composition (X-ray diffraction) analysis. As a result, it was found that an increase in the $\mathrm{Al}_{2} \mathrm{O}_{3}$ content in the HAC clinker resulted in an increase in the diffusion coefficient and concentration of surface chloride due to increased binding of chloride. However, types of HAC did not affect the pore distribution in the cement matrix, except for macro pores.

\section{Introduction}

High alumina cement (HAC), mainly consisting of aluminum oxide $\left(\mathrm{Al}_{2} \mathrm{O}_{3}\right)$ from about 50 to $85 \%$ in cement clinker, could be often used for a special application, due to both high resistance to aggressive chemical ions (i.e., sewer concrete) and rapid development of strength within 24 hours [1-4]. However, its use in concrete structures has been severely restricted by the loss of strength in the process of conversion; metastable hydrates $\left(\mathrm{CaO} \cdot \mathrm{Al}_{2} \mathrm{O}_{3} \cdot 10 \mathrm{H}_{2} \mathrm{O}, \mathrm{CAH}_{10}\right.$; $2 \mathrm{CaO} \cdot \mathrm{Al}_{2} \mathrm{O}_{3} \cdot 8 \mathrm{H}_{2} \mathrm{O}, \mathrm{C}_{2} \mathrm{AH}_{8}$ ) are transformed to stable ones $\left(3 \mathrm{CaO} \cdot \mathrm{Al}_{2} \mathrm{O}_{3} \cdot 6 \mathrm{H}_{2} \mathrm{O}, \mathrm{C}_{3} \mathrm{AH}_{6}\right)$ as follows [5-8]:

$$
\begin{aligned}
& 3 \mathrm{CAH}_{10} \longrightarrow \mathrm{C}_{3} \mathrm{AH}_{6}+2 \mathrm{AH}_{3}+18 \mathrm{H} \\
& 3 \mathrm{C}_{2} \mathrm{AH}_{8} \longrightarrow 2 \mathrm{C}_{3} \mathrm{AH}_{6}+2 \mathrm{AH}_{3}+9 \mathrm{H}
\end{aligned}
$$

Due to the release of water molecules in the conversion, however, further hydration of anhydrous phases in cement matrix progresses steadily $[1,2,9]$, thereby compensating for the reduced strength and thus the required performance in structural members. Thus, HAC may be used for structural concrete structures, under the condition that rapid hydration is arrested in situ by any means, together with reduced economic price.

It is also intuitively supported that the high portion of aluminum oxide in $\mathrm{HAC}$, which is in fact related to formation of CA-type hydration, for example, $\mathrm{C}_{3} \mathrm{~A}$, to remove free chlorides from the concrete pore solution, might be preferred to enhance resistance to chloride-induced corrosion of steel in concrete [10]. Steel embedment in concrete is usually protected by the passive layer (i.e., $\gamma-\mathrm{Fe}_{2} \mathrm{O}_{3}$ ), formed in a high alkaline environment, in which the value of $\mathrm{pH}$ accounts for about 12.0 up to 13.5 [11], although chloride ions at the depth of the steel in concrete would subsequently depassivate the steel surface, followed by corrosion propagation to the entire surface of steel $[12,13]$. Simultaneously, corrosion of steel could be more or less mitigated by the removal of free chloride ions in the pore solution. In the majority of previous studies [14, 15], the increased binding capacity of HAC paste enabled more adsorption and binding of chloride ions in the pore solution to mitigate the risk of chloride-induced corrosion. In fact, the corrosion resistance of HAC in terms of critical chloride concentration for the onset of corrosion was increased up to $2.4 \%$, whilst OPC concrete ranged from $0.2 \%$ to $1.0 \%$ for the chloride threshold [10] 
TABLE 1: Oxide composition and chemical properties of different HAC types.

\begin{tabular}{lccccccccccc}
\hline & \multicolumn{1}{c}{ Oxide composition (\%) } & & & \multirow{2}{*}{ Ignition loss (\%) } & Fineness (cm $\left.{ }^{2} / \mathrm{g}\right)$ & Density \\
& $\mathrm{CaO}$ & $\mathrm{Al}_{2} \mathrm{O}_{3}$ & $\mathrm{SiO}_{2}$ & $\mathrm{Fe}_{2} \mathrm{O}_{3}$ & $\mathrm{SO}_{3}$ & $\mathrm{MgO}$ & $\mathrm{K}_{2} \mathrm{O}$ & $\mathrm{Na}_{2} \mathrm{O}$ & $\mathrm{MnO}$ & & 5,150 \\
HAC I & 38.83 & 52.03 & 5.02 & 0.86 & 0.09 & 0.42 & 0.68 & 0.17 & 0.03 & 0.50 & 3.03 \\
HAC II & 32.01 & 67.25 & 0.11 & 0.08 & 0.01 & 0.21 & 0.01 & 0.28 & 0.02 & 0.61 & 4,800 \\
HAC III & 18.35 & 81.09 & 0.06 & 0.06 & 0.01 & 0.08 & 0.01 & 0.32 & 0.01 & 1.21 & 2.92 \\
\hline
\end{tabular}

When it comes to the corrosion-free service life of structures, the rate of chloride transport in HAC concrete, however, is of no concern to date. As chloride transport is affected by the distribution of pores and simultaneously the reactivity of the cement matrix with chloride ions, predicting the corrosion-free life must be accompanied by the rate of chloride transport. In particular, HAC concrete imposes the increased pores in the process of conversion from the hexagonal to cubic phases, which may accelerate the chloride permeation and offset the benefit in increasing the resistance to chloride-induced corrosion. Moreover, the binding capacity of HAC concrete may affect the buildup of chloride ions on the surface of concrete, when immersed in a salt solution, which subsequently would increase the diffusivity of chloride ions.

To ensure the characteristics of chloride transport in HAC concrete, the rate of chloride transport in terms of diffusivity was investigated by an exposure test in this study. Refinement of the pore structure was examined by the intrusion of mercury into a specimen to quantify the influence of conversion on the pore distribution. Simultaneously, the chloride binding capacity of HAC paste was determined to assess its effect on both corrosion resistance and chloride transport. Three different HAC types were used containing $52.0,67.3$, and $81.1 \%$ of aluminum oxides in HAC clinker.

\section{Experimental Works}

2.1. Compressive Strength and Penetration Resistance. The oxide composition of HAC used in the present study was determined by X-ray fluorescence (XRF) and physical properties of HAC are given in Table 1. For the development of the compressive strength, mortar specimens were fabricated in a cylindrical mould $(\varnothing 100 \times 200 \mathrm{~mm})$. Mix proportion for the cement: water: sand (Grade M) was $1.00: 0.40: 2.45$. The specific gravity of sand was 2.65 . This mix proportion for mortar was subsequently used for the chloride profile and mercury intrusion porosimetry. The mortar specimens were demoulded in 12 hours after casting and then cured in a wet chamber at $25 \pm 2^{\circ} \mathrm{C}$ to reduce the influence on the transformation of hexagonal to cubic phases in hydration products. The compressive strength for mortar specimens was measured at various ages to monitor the influence of the conversion process in the HAC mortar on the strength development.

A fresh mortar was poured in a cubic mould $(100 \times$ $100 \times 400 \mathrm{~mm}$ ) to determine the penetration resistance with time and was subsequently measured by a set of standard needles $\left(16,32,65,161,312\right.$, and $645 \mathrm{~mm}^{2}$ in diameter) at a given time interval. After interpolating the curve for the penetration resistance with time, the setting time was determined, assuming that the initial and final sets are defined as time for the penetration resistance to reach 3.43 and $27.46 \mathrm{MPa}$, respectively.

2.2. Chloride Profile. The mortar specimens fabricated in the cylindrical mould $(\varnothing 100 \times 200 \mathrm{~mm})$ were cured in an identical wet chamber for 91 days to maximise the hydration degree, and then the specimens were cut into $50 \mathrm{~mm}$ thickness, in which all the surfaces were coated by epoxy resin except for one surface to induce one-way chloride penetration. Then, the mortar disks $(\varnothing 100 \times 50 \mathrm{~mm})$ were immersed in a $1.0 \mathrm{M} \mathrm{NaCl}$ solution for 100 days, followed by grinding the specimens every $5 \mathrm{~mm}$ depth increments up to $20 \mathrm{~mm}$ from the specimen surface to measure chloride concentration in each sample. The obtained sample was stirred for $5 \mathrm{~min}$ in $50 \mathrm{~mL}$ distilled water at $50^{\circ} \mathrm{C}$ to extract the water-soluble chloride, and then, for reaching a chemical equivalent in solution, a further $30 \mathrm{~min}$ of standing was carried out. After filtering the sample, the concentration of chloride ion in sample was measured by the titration method using ion selective electrode (ISE) for chloride. An identical procedure was adopted to determine the acid soluble chloride concentration using 2.0 nitric acid $\left(\mathrm{HNO}_{3}\right)$ for solvent instead of distilled water.

Once the total and free chloride concentrations were obtained at all depths, the surface chloride $\left(C_{S}\right)$ and an apparent diffusion coefficient $\left(D_{\text {app }}\right)$ were determined by fitting to the error function solution to Fick's second law for nonsteady state, given by

$$
C(x, t)=C_{S}\left(1-\operatorname{erf} \frac{x}{2 \sqrt{D t}}\right),
$$

where $C(x, t)$ is chloride concentration at depth $x$ after time $t\left(\% / \mathrm{m}^{3}\right), C_{S}$ is surface chloride concentration $\left(\% / \mathrm{m}^{3}\right), x$ is depth $(\mathrm{mm}), D$ is apparent diffusion coefficient $\left(\mathrm{m}^{2} / \mathrm{s}\right)$, and $t$ is time of exposure (s).

When free chloride concentration was determined at a given total, the chloride binding capacity was represented by the Langmuir isotherm. In this study, water-soluble chlorides were taken as free, while acid soluble ones were taken as total chlorides. The concentration of bound chloride ions was determined by subtracting the free chloride concentration from the total.

2.3. Chlorides in the Matrix. The X-ray diffraction method was used to identify the bound chlorides in the HAC paste. To react with chlorides from an external environment, a thin layered HAC paste $(\varnothing 100 \times 5 \mathrm{~mm})$ at 0.4 of a free 
W/C was immersed in $1.0 \mathrm{M} \mathrm{NaCl}$ solution for 100 days. Then, the specimens were immersed in isopropanol for 7 days to prevent further hydration, followed by remaining in a dessicator for 1 day to remove/evaporate the residual waterbased solvent. After removing water, the paste specimen was ground and sieved with the $300 \mu \mathrm{m}$ sieve to obtain the dust sample, which was analysed with D/MAX-2500 model (Rigaku) and Jade 9.5 software. The scan range was from 5 to $45^{\circ}$ of $2 \theta$ at a scan rate of $4^{\circ} / \mathrm{min}$.

2.4. Pore Structure Examination. To examine the pore distribution at a given pore diameter, the HAC mortar specimens were fabricated in a cylindrical mould $(\varnothing 10 \times 10 \mathrm{~mm})$ and cured for 91 days in the wet chamber at $25 \pm 2^{\circ} \mathrm{C}$. Prior to examining the pore structure, the residual water in the specimen was removed by an identical method for the Xray diffraction test. The porosimeter used in this study was Autopore IV 9500 model (Micromeritics Instrument) to fit the low and high pressure. The first step was applied by low pressure of mercury $(\mathrm{Hg})$ up to 0.51 psia using nitrogen gas to measure macroporosity, and then the maximum pressure was gradually increased to 33,000 psia for microporosity. The pore volume versus pore diameter calculated by the Washburn equation at a given pressure was plotted in the cumulative pore volume and incremental curve. Hence,

$$
d=\frac{-4 \gamma \cos \theta}{P}
$$

where $d$ is pore diameter $(\mathrm{m}), \gamma$ is surface tension $(\mathrm{N}), \theta$ is contact angle $\left({ }^{\circ}\right)$, and $P$ is pressure (MPa).

\section{Results and Discussion}

3.1. Compressive Strength and Penetration Resistance. The penetration resistance of fresh HAC mortar with time is given in Figure 1. The initial and final sets were determined by the best-fitted curve for the penetration resistance with time $\left(y=a e^{b x}\right)$. It was seen that the setting time was strongly dependent on the HAC type; an increase in the $\mathrm{Al}_{2} \mathrm{O}_{3}$ content in clinker resulted in an increase in the time for the initial and final sets. For example, the time for the initial and final sets of HAC I imposed the rapid hardening, accounting for 185 and $230 \mathrm{~min}$ for the initial and final sets, respectively, while HAC III indicated $291 \mathrm{~min}$ and $409 \mathrm{~min}$, respectively. The HAC is usually divided into three groups: (1) low alumina (50-60\% in $\left.\mathrm{Al}_{2} \mathrm{O}_{3}\right),(2)$ medium alumina (65-75\% in $\mathrm{Al}_{2} \mathrm{O}_{3}$ ), and (3) high alumina ( $>80 \%$ in $\mathrm{Al}_{2} \mathrm{O}_{3}$ ). The anhydrous phases consist of $\mathrm{CA}$, a main hydraulic constituent in HAC, $\alpha$ $\mathrm{Al}_{2} \mathrm{O}_{3}, \mathrm{C}_{12} \mathrm{~A}_{7}$, and $\mathrm{CA}_{2}$, being significant, according to raw materials. Guirado and Galí [16] showed that an increase in ratio of $\mathrm{CaO} / \mathrm{Al}_{2} \mathrm{O}_{3}$ (hereinafter $\mathrm{C} / \mathrm{A}$ ) resulted in both an increase in $\mathrm{CA}_{2}$ content and a decrease in $\mathrm{CA}$ ones, measured by the Rietveld analysis. As the hydration process in $\mathrm{HAC}$ is governed by the amount of $\mathrm{Ca}^{2+}$ and $\mathrm{Al}(\mathrm{OH})_{4}{ }^{-}$ ions in solution, the quantities and solubility in each clinker could be influencing the development of the strength. Klaus et al. [17] investigated the hydration of mixture of CA and $\mathrm{CA}_{2}$ (W/C ratio: 0.45 ; curing temp.: $23 \pm 0.2^{\circ} \mathrm{C}$ ) in terms

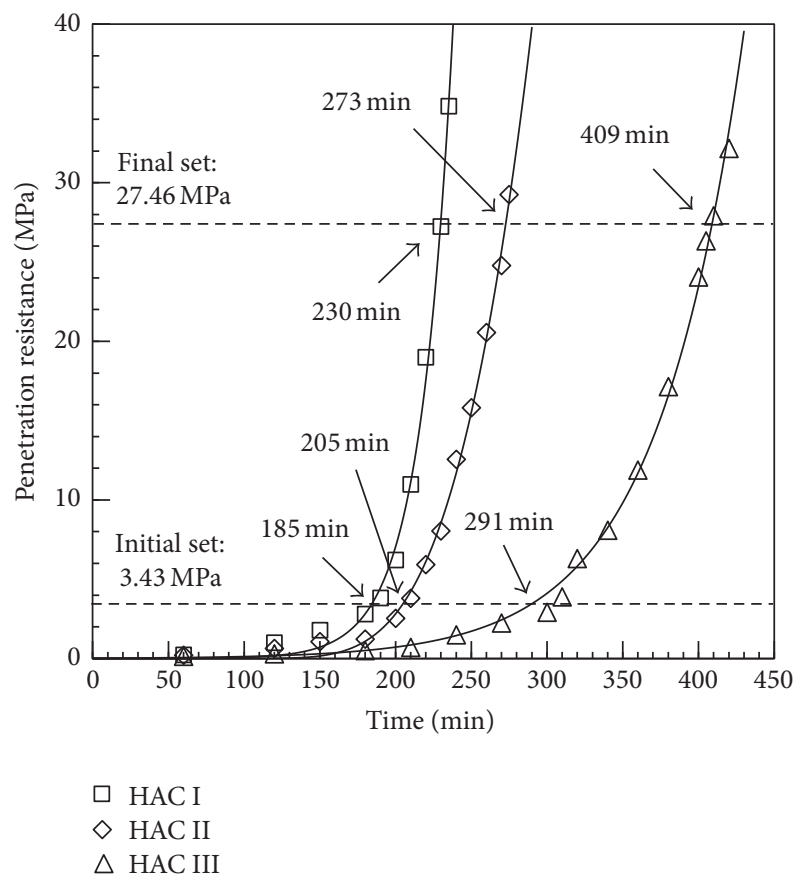

FIgURE 1: Penetration resistance of fresh concrete with time to determine the setting time for different HAC types.

of their dissolution. They found that the dissolution of CA progressively appeared at the initial stage (up to about 6 hours), followed by that of $\mathrm{CA}_{2}$. Moreover, the dissolution behaviour of $\mathrm{CA}$ was constant in the presence of various $\mathrm{CA}_{2}$ content. In addition, it was reported that CA in HAC clinker is reactive more than $\mathrm{CA}_{2}$ at ambient temperature $\left(20-30^{\circ} \mathrm{C}\right)$ [18]. Consequently, as CA leads to rapid setting and hardening at the early stage in the process of hydration, it is possible to control the setting behaviour for HAC by modifying the $\mathrm{C} / \mathrm{A}$ ratio in clinker at the manufacturing step.

The compressive strength of mortar with different HAC types was measured at 1-91 days as shown in Figure 2. As expected, the strength for HAC mortar rapidly increased with time at an early age, regardless of types, up to 7 days, and then decreased at 14 days, except for HAC I. In particular, the strength of HAC I mortar showed a considerable high strength at an early age, reaching beyond $66.3 \mathrm{MPa}$ at 7 days, and then gradually decreased to $47.7 \mathrm{MPa}$ at 56 days, while HAC III mortar faced a sudden decease from 65.1 MPa at 7 days to $51.4 \mathrm{MPa}$ at 14 days. The high early compressive strength is attributed to an inherent characteristic of HAC, which may be attributed to rapidly elevated heat (up to about $90^{\circ} \mathrm{C}$ in adiabatic temperature) during hydration within $10-$ 12 hours [1]. A reduction of the compressive strength may reflect the conversion process from the hexagonal $\left(\mathrm{CAH}_{10}\right.$ and $\left.\mathrm{C}_{2} \mathrm{AH}_{8}\right)$ to cubic $\left(\mathrm{C}_{3} \mathrm{AH}_{6}\right)$ phases during hydration of HAC paste, accompanying the densified matrix, and thus in turn increased porosity in the cement matrix $[6,7]$. It is notable that a marginal increase for compressive strength was observed after 14 days of curing in all types. It is evident that further hydration of anhydrous phases, such as $\mathrm{CA}, \mathrm{CA}_{2}$, and $\mathrm{C}_{12} \mathrm{~A}_{7}$, may maintain a certain strength, despite a risk of the 


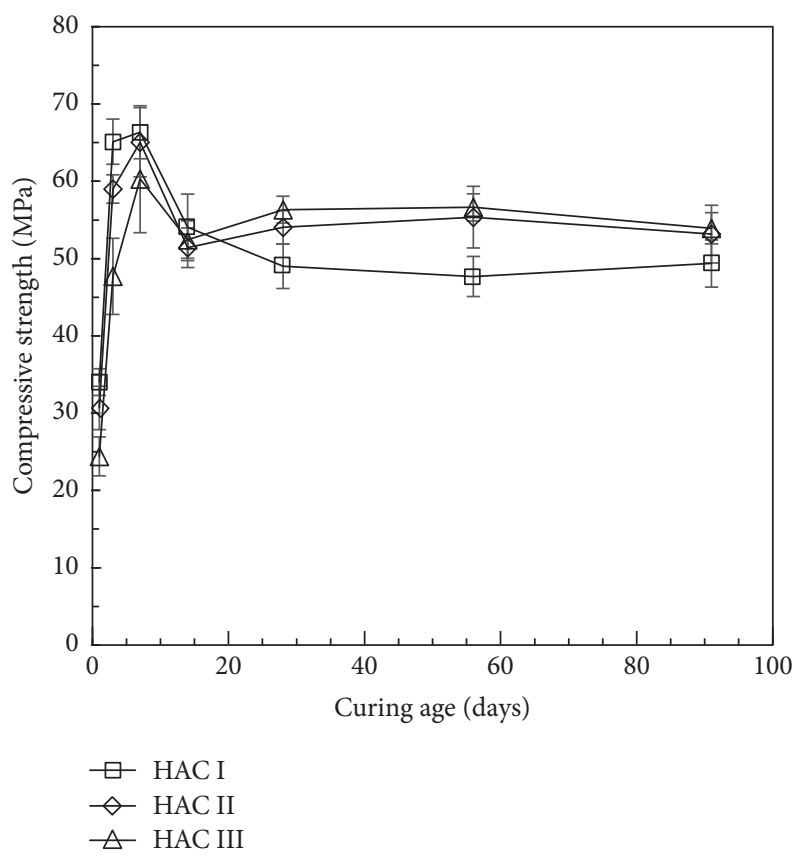

FIGURE 2: Development of compressive strength of mortar for different HAC types with curing age.

conversion process, which is, in fact, related to generation of porosity and in turn may decrease the concrete strength $[6,7]$. Substantially, all the mortar compressive strengths achieved a high level of their ultimate compressive strength, exceeding about $50 \mathrm{MPa}$ at 91 days, which could not seem to further increase or decrease. Thus, it can be said that there would be no adverse effect in using the HAC for structural concrete, presumably due to the unstable development of the compressive strength.

3.2. Chloride Transport. After exposure of mortar specimens to the $1.0 \mathrm{NaCl}$ solution for 100 days, the chloride concentration was measured at each depth with increments of $5.0 \mathrm{~mm}$ for the acid- and water-soluble chlorides, corresponding to total and free chlorides, respectively. Then, the chloride profile was used to determine the apparent diffusion coefficient of chlorides and the surface chloride content for nonsteady state by fitting to the error function solution to Fick's second law, as shown in Figure 3. It is obvious that an increase in the $\mathrm{C} / \mathrm{A}$ ratio (i.e., lower content of $\mathrm{Al}_{2} \mathrm{O}_{3}$ in oxides in HAC clinker) resulted in a decrease in the chloride ingress at every depth. In particular, the concentration of total surface chloride was strongly dependent on the $\mathrm{C} / \mathrm{A}$ ratio in cement. For example, $\mathrm{HAC} \mathrm{I}$ at the higher C/A ratio produced $0.84 \%$ of the surface chloride by weight of cement, while HAC III increased up to $2.08 \%$. This may be ascribed to the chemical equilibrium for chloride ions at the interface between specimen surface and solution. The higher $\mathrm{Al}_{2} \mathrm{O}_{3}$ content in cement clinker would enhance the formation of chloroaluminate hydrates, which often would result from a reaction between cement paste and free chlorides to remove/immobilise them from the pore solution $[10,19]$. The higher chloride binding capacity, resulting from increased $\mathrm{C}_{3} \mathrm{~A}$ content, may impose increased concentration of bound chloride on the surface of concrete at a given free chloride concentration due to the chemical balance between concrete surface and saline media [20]. Thus, the lower C/A ratio in HAC may enhance the buildup of chlorides on the concrete surface, leading to an increase in the concentration gradient to accelerate the rate of chloride transport.

It is evident that the diffusion coefficient of chlorides was much affected by the C/A ratio in HAC. In fact, an increase in the $\mathrm{C} / \mathrm{A}$ resulted in a decrease in the diffusion coefficient. For example, the HAC I produced the lowest diffusivity of $1.61 \times 10^{-11} \mathrm{~m}^{2} / \mathrm{s}$, while HAC II and HAC III indicated 1.85 $\times 10^{-11} \mathrm{~m}^{2} / \mathrm{s}$ and $2.17 \times 10^{-11} \mathrm{~m}^{2} / \mathrm{s}$, respectively. However, the diffusion coefficient calculated for free chloride transport had no significant effect arising from different $\mathrm{C} / \mathrm{A}$ ratios; the diffusion coefficient for free chlorides in HAC was in a small range from $1.31 \times 10^{-11}$ to $1.43 \times 10^{-11} \mathrm{~m}^{2} / \mathrm{s}$, irrespective of types of HAC. The rate of chloride transport is affected by the pore structure (i.e., distribution of capillary pores in the cement matrix) and chemical reactivity between cement paste and chloride ions, such as chloride binding. The HAC paste is always subjected to the conversion process from the hexagonal phases $\left(\mathrm{CAH}_{10}\right.$ and $\left.\mathrm{C}_{2} \mathrm{AH}_{8}\right)$ to cubic phases $\left(\mathrm{C}_{3} \mathrm{AH}_{6}\right)$, depending on the curing regime, temperature, and $\mathrm{C} / \mathrm{A}$ ratio, which subsequently may govern the pore structure. Simultaneously, the reactivity between cement paste and chloride ions in HAC would be very accelerated rather than in OPC, due to increased formation of reactive hydration products such as $\mathrm{CA}, \mathrm{CA}_{2}$, and $\mathrm{C}_{12} \mathrm{~A}_{7}$. Thus, these influencing factors must be quantified to determine the chloride transport in HAC concrete. For example, examination of the chloride binding capacity and the pore structure must be accompanied.

3.3. Chloride Binding. To render the binding isotherm, the relation between free and bound chlorides for different HAC types was depicted in Figure 4, using the Langmuir isotherm. The concentration of free and bound chloride was determined in the process of chloride profiling at different depths and at different total chloride concentrations. As expected, an increase in the free chloride concentration resulted in an increase in the bound chlorides, regardless of the HAC types. It is evident that the $\mathrm{C} / \mathrm{A}$ ratio was significantly influencing the chloride binding capacity at a given total chloride concentration. In fact, HAC III was ranked the highest chloride binding capacity, presumably arising from increased Al-based clinkers, which subsequently would form the CA-type hydrates to arrest chlorides into Friedel's salt. Due to a marginal difference in the $\mathrm{pH}$ of the pore solution, the $\mathrm{pH}$ seems to be less influencing on the chloride binding capacity [15], and the conversion process in the HAC matrix is, moreover, less affected. Substantially, the binding of chlorides into a crystallised form may solely be affected by the concentration of $\mathrm{Al}_{2} \mathrm{O}_{3}$ in clinker, although other hydration products may contribute to the reaction with chlorides in a limited margin.

The HAC paste immersed in the $\mathrm{NaCl}$ solution was analysed by X-ray diffraction as seen in Figure 5. It is seen that the peaks for hydration products were mostly 


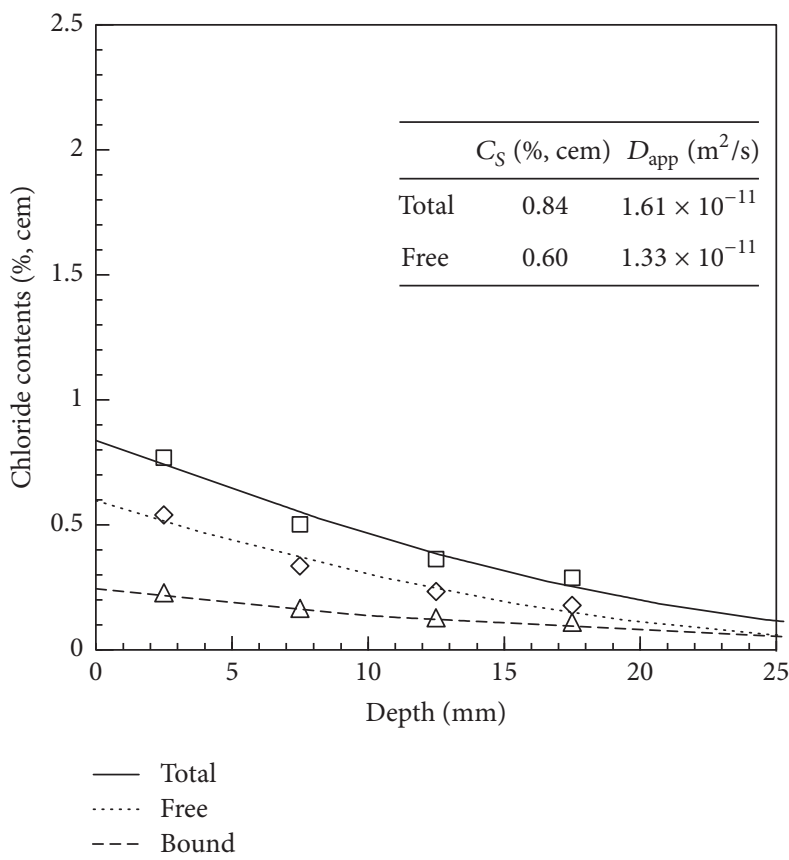

(a) HAC I

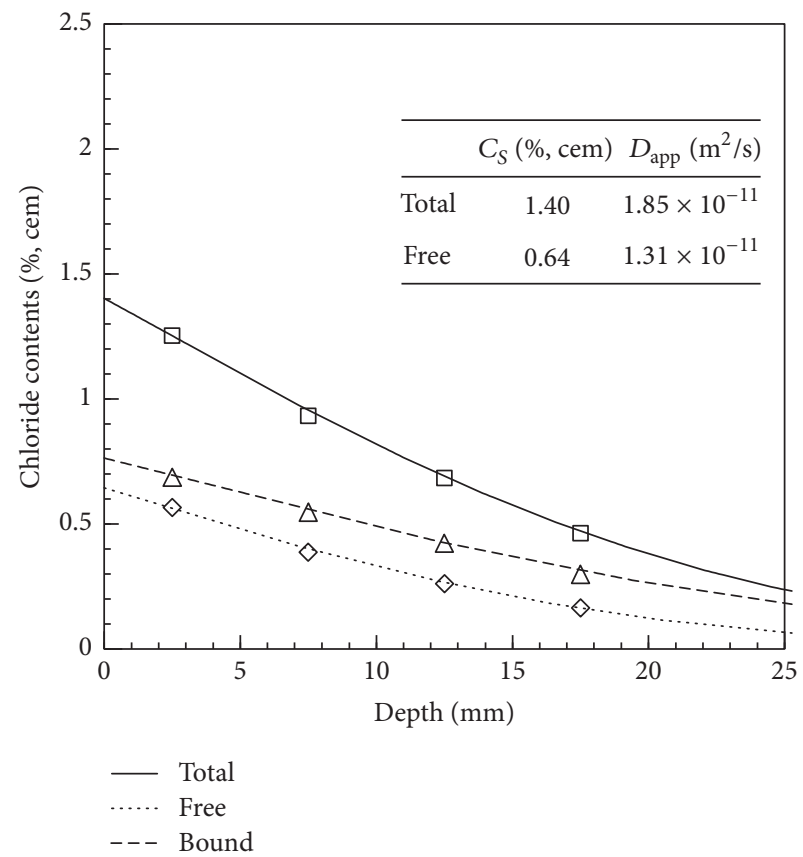

(b) HAC II

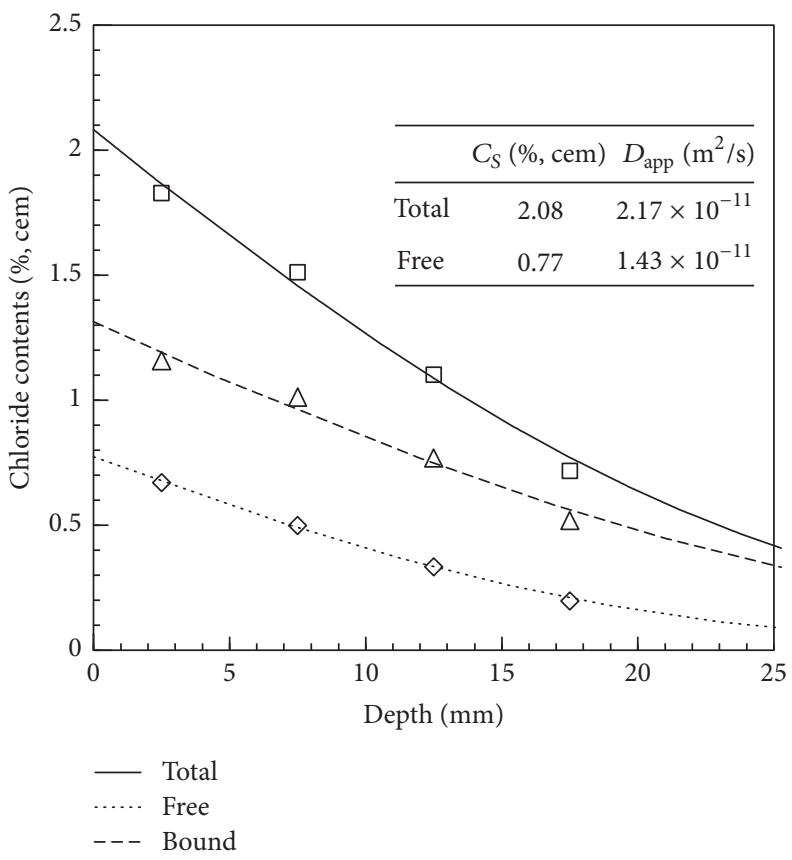

(c) HAC III

FIGURE 3: Chloride profiles of mortar for different HAC types after 100 days of exposure to $1.0 \mathrm{M} \mathrm{NaCl}$ solution.

identical between HAC pastes, imposing similar generation of hydration, except for unreactive $\alpha-\mathrm{Al}_{2} \mathrm{O}_{3}$ in HAC III. It is notable that no metastable crystals $\left(\mathrm{CAH}_{10}\right.$ and $\left.\mathrm{C}_{2} \mathrm{AH}_{8}\right)$ were identified for all the HAC types in the $\mathrm{X}$-ray diffraction curves, implying that the hexagonal phases formed in the cement matrix were completely converted to cubic phases during curing consisting of 91 days of wet curing and 100 days of exposure to a salt solution at $25 \pm 2^{\circ} \mathrm{C}$. The high intensity was commonly observed at $11.0-11.2^{\circ}$ of $2 \theta$ in HAC pastes, indicating that Friedel's salt was quite formed, depending on the $\mathrm{C} / \mathrm{A}$ ratio. In fact, an increase in the $\mathrm{C} / \mathrm{A}$ resulted in a decrease in Friedel's salt. This may confirm that the high content of $\mathrm{Al}_{2} \mathrm{O}_{3}$ may be of benefit in forming Friedel's salt, due to increased possibilities of the formation of chloridereactive CA hydration products.

3.4. Pore Structure. The pore distribution in the HAC mortar was determined by mercury intrusion porosimetry, as given 


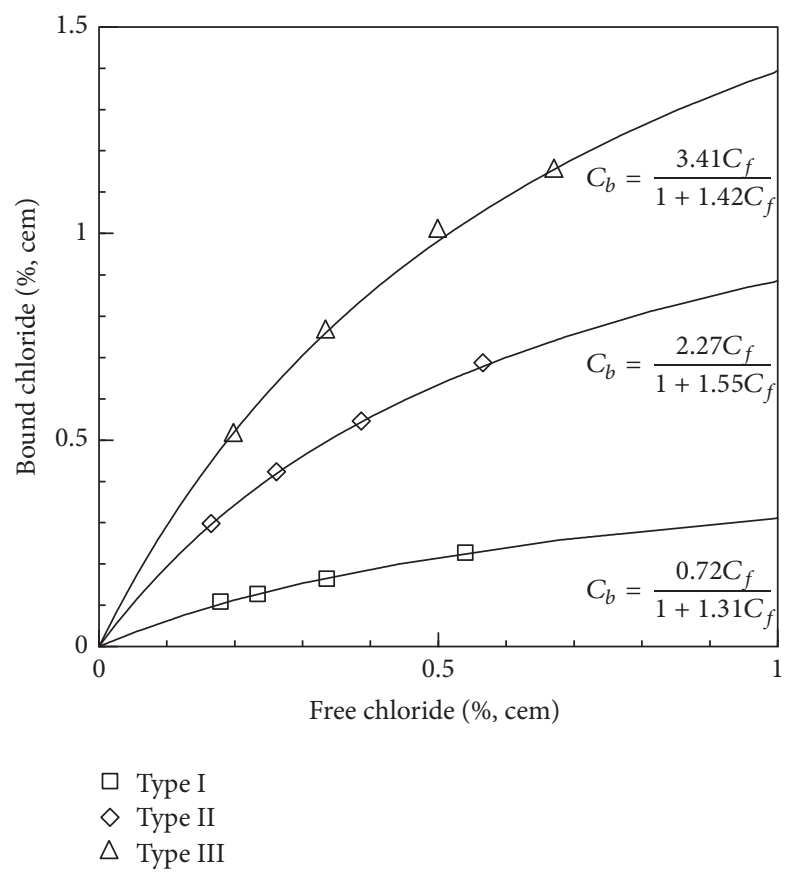

FIGURE 4: Relation between free and bound chlorides at a given total chloride concentration in cement mortar with different HAC types after 100 days of exposure to $1.0 \mathrm{M} \mathrm{NaCl}$ solution (expressed by the Langmuir isotherm).

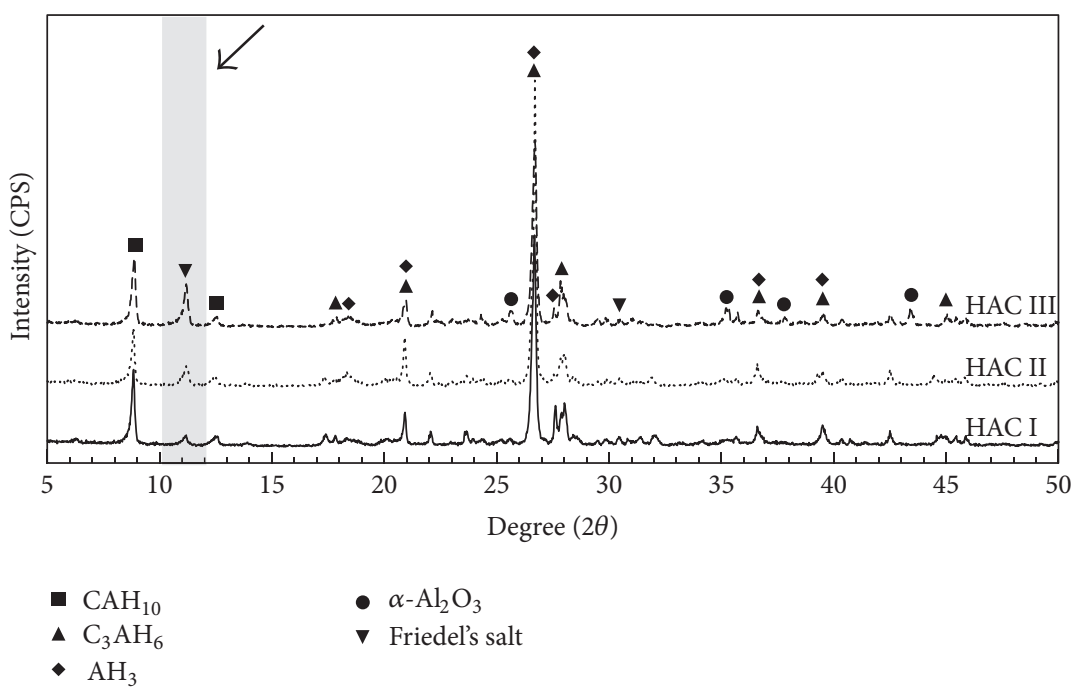

(a)

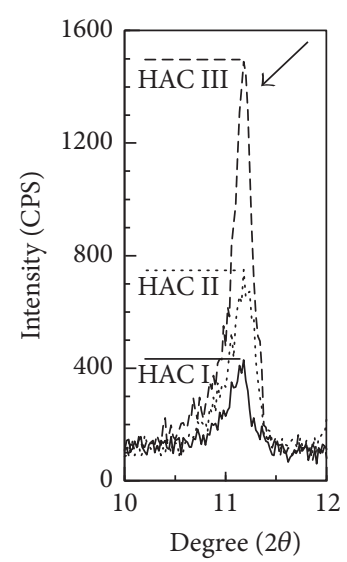

(b)

Figure 5: X-ray diffraction pattern of cement paste with different $\mathrm{HAC}$ types after 100 days of exposure to $1.0 \mathrm{M} \mathrm{NaCl}$ solution. (a) Hydration products and (b) Friedel's salt.

in Figure 6, together with incremental pores at different sizes. Irrespective of types of HAC, the total pore volume was in the range of $0.076-0.088 \mathrm{~mL} / \mathrm{g}$. The distribution of capillary pore was not much affected by the types of HAC, which would provide paths for ions to transport in the form of interrelated network. However, macro pore distribution was dependent on the HAC types; an increase in the C/A resulted in an increase in the volume of macro pores, which are not interconnected with the capillary pore and thus may block the ionic transport [21]. As seen in Figure 3, the
HAC III produced the highest rate of chloride transport in terms of apparent chloride diffusion coefficient. This may be attributed to a lower volume of the macro pores, enhancing the connectivity between pores and thus chloride transport. Moreover, a reduction of the macro pore volume may increase the development of the concrete strength at a given hydration degree; in fact, HAC III was ranked the highest strength as seen in Figure 2 after 14-28 days of curing. Despite further generation of the pores in the conversion process from the hexagonal to cubic phases, a modified pore structure after the 


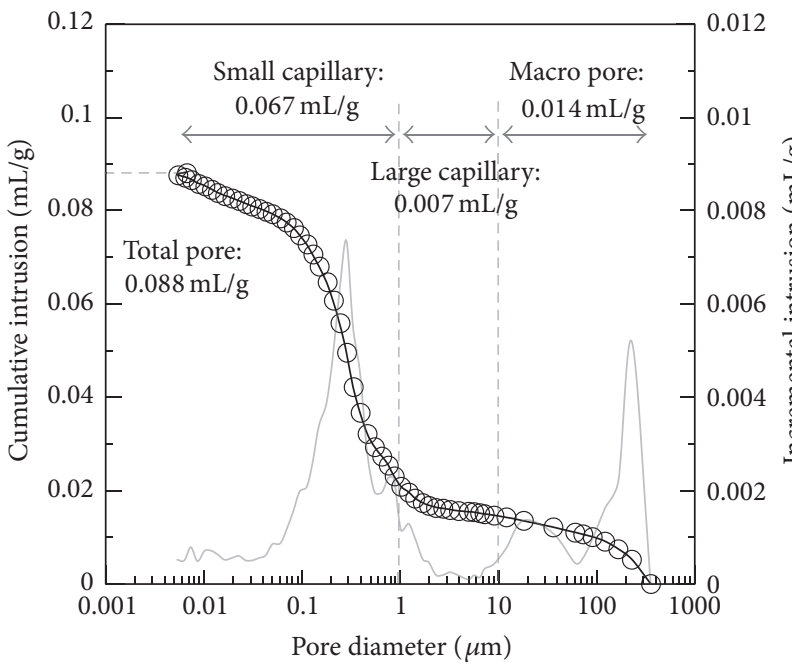

(a) HAC I

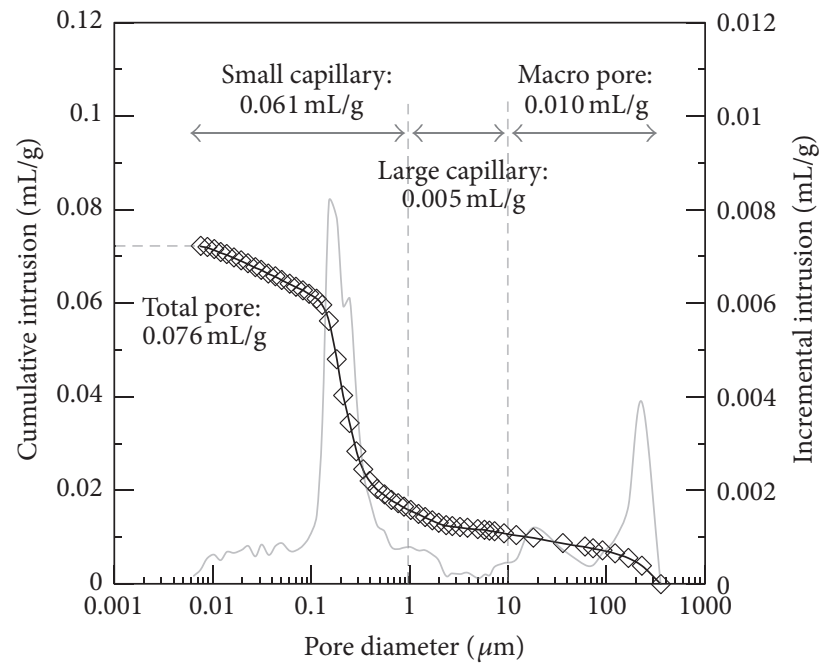

(b) HAC II

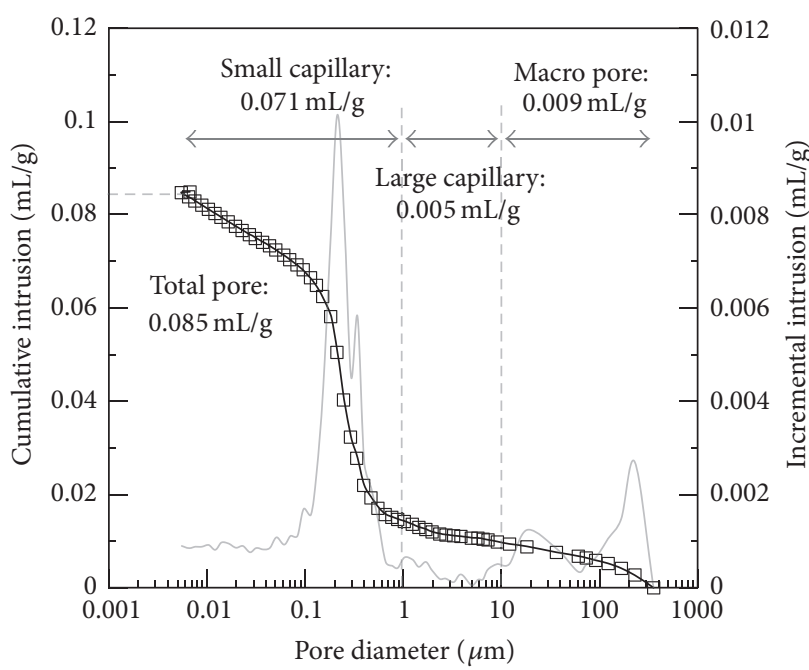

(c) HAC III

FIGURE 6: Pore size distribution of mortar to a given pore diameter with different HAC types.

conversion was not identified in this study, because the pore distribution before the conversion process, presumably at a very early age, was not obtained.

\section{Conclusion}

In this study, the ionic transport in different types of HAC mortar was investigated by the chloride profile, which was supported by further experimentation including an examination of the pores structure, chloride binding capacity, and chemical microscopic analysis (X-ray diffraction analysis). The $\mathrm{HAC}$ was classified by the content of $\mathrm{Al}_{2} \mathrm{O}_{3}$ in cement clinker ranging from 52.0 to $81.1 \%$. Simultaneously, development of the compressive strength and setting time were measured to secure their applicability in situ. Detailed experimental results and conclusion derived from the study are given as follows:

(1) An increase in the $\mathrm{Al}_{2} \mathrm{O}_{3}$ in the HAC clinker resulted in an increase in the setting time, and, moreover, the gap between initial and final sets was also increased, due to increased $\mathrm{CA}_{2}$ formation. HAC mortars gained rapidly the compressive strength at an early age, accounting for 66.3 $\mathrm{MPa}$ at 7 days, which was reduced at 14 days of curing presumably due to the conversion process from the hexagonal to cubic phases and then again marginally increased or/and converged to a certain level up to 91 days, ranging from 49.36 to $53.92 \mathrm{MPa}$.

(2) The apparent diffusion coefficient and surface chloride concentration of HAC mortars immersed in a salt solution were obtained by profiling of chloride concentration at each depth. An increase in the $\mathrm{Al}_{2} \mathrm{O}_{3}$ in $\mathrm{HAC}$ clinker resulted in an increase in the surface chloride and diffusion coefficient, due to increased chloride binding capacity and modified pore structure. The surface chloride ranged from 0.84 to $2.08 \%$, while the diffusion coefficient of chlorides in HAC mortar was in the range of $1.61-2.17 \mathrm{~m}^{2} / \mathrm{s}$. 
(3) The chloride binding capacity, rendered by the Langmuir isotherm, was increased by $\mathrm{Al}_{2} \mathrm{O}_{3}$ in $\mathrm{HAC}$ clinker, which would form CA-type hydration products to react with chloride ions into Friedel's salt. However, types of HAC did not have an influence on the pore distribution in the cement matrix, except for macro pores.

\section{Competing Interests}

The authors declare that they have no competing interests.

\section{Acknowledgments}

This research was supported by the research fund of Hanyang University (HY-2012-N).

\section{References}

[1] P. C. Hewlett, Lea's Chemistry of Cement and Concrete, Elsevier, 4th edition, 2013.

[2] J. Newman and B. S. Choo, Advanced Concrete TechnologyConstituent Materials, Elsevier, 2003.

[3] H. Pöllmann, "Calcium aluminate cements-raw materials, differences, hydration and properties," Reviews in Mineralogy \& Geochemistry, vol. 74, no. 1, pp. 1-82, 2012.

[4] S. M. Bushnell-Watson and J. H. Sharp, "The effect of temperature upon the setting behaviour of refractory calcium aluminate cements," Cement and Concrete Research, vol. 16, no. 6, pp. 875$884,1986$.

[5] A. M. Neville, Properties of Concrete, Longman Group, 4th edition, 1995.

[6] H. G. Midgley and A. Midgley, "The conversion of high alumina cement," Magazine of Concrete Research, vol. 27, no. 91, pp. 5977, 1975.

[7] C. Bradbury, P. M. Callaway, and D. D. Double, "The conversion of high alumina cement/concrete," Materials Science and Engineering, vol. 23, no. 1, pp. 43-53, 1976.

[8] R. J. Collins and W. Gutt, "Research on long-term properties of high alumina cement concrete," Magazine of Concrete Research, vol. 40, no. 145, pp. 195-208, 1988.

[9] J. Bensted and P. Barnes, Structure and Performance of Cements, Taylor \& Francis Group, 2nd edition, 2002.

[10] K. Y. Ann, T.-S. Kim, J. H. Kim, and S.-H. Kim, "The resistance of high alumina cement against corrosion of steel in concrete," Construction and Building Materials, vol. 24, no. 8, pp. 15021510, 2010.

[11] C. L. Page, "Mechanism of corrosion protection in reinforced concrete marine structures," Nature, vol. 258, no. 5535, pp. 514515, 1975.

[12] M. Saremi and E. Mahallati, "A study on chloride-induced depassivation of mild steel in simulated concrete pore solution," Cement and Concrete Research, vol. 32, no. 12, pp. 1915-1921, 2002.

[13] K. Y. Ann and H.-W. Song, "Chloride threshold level for corrosion of steel in concrete," Corrosion Science, vol. 49, no. 11, pp. 4113-4133, 2007.

[14] A. Macias, A. Kindness, and F. P. Glasser, "Corrosion behaviour of steel in high alumina cement mortar cured at 5,25 and $55^{\circ} \mathrm{C}$ : chemical and physical factors," Journal of Materials Science, vol. 31, no. 9, pp. 2279-2289, 1996.

[15] M. A. Sanjuán, "Formation of chloroaluminates in calcium aluminate cements cured at high temperatures and exposed to chloride solutions," Journal of Materials Science, vol. 32, no. 23, pp. 6207-6213, 1997.

[16] F. Guirado and S. Galí, "Quantitative Rietveld analysis of CAC clinker phases using synchrotron radiation," Cement and Concrete Research, vol. 36, no. 11, pp. 2021-2032, 2006.

[17] S. R. Klaus, J. Neubauer, and F. Goetz-Neunhoeffer, "Hydration kinetics of $\mathrm{CA}_{2}$ and CA-investigations performed on a synthetic calcium aluminate cement," Cement and Concrete Research, vol. 43, no. 1, pp. 62-69, 2013.

[18] A. Rettel, R. Seydel, W. Gessner, J. P. Bayoux, and A. Capmas, "Investigations on the influence of alumina on the hydration of monocalcium aluminate at different temperatures," Cement and Concrete Research, vol. 23, no. 5, pp. 1056-1064, 1993.

[19] K. Y. Ann and C.-G. Cho, "Corrosion resistance of calcium aluminate cement concrete exposed to a chloride environment," Materials, vol. 7, no. 2, pp. 887-898, 2014.

[20] G. K. Glass and N. R. Buenfeld, "The influence of chloride binding on the chloride induced corrosion risk in reinforced concrete," Corrosion Science, vol. 42, no. 2, pp. 329-344, 2000.

[21] G. K. Glass and N. R. Buenfeld, "Chloride-induced corrosion of steel in concrete," Progress in Structural Engineering and Materials, vol. 2, no. 4, pp. 448-458, 2000. 

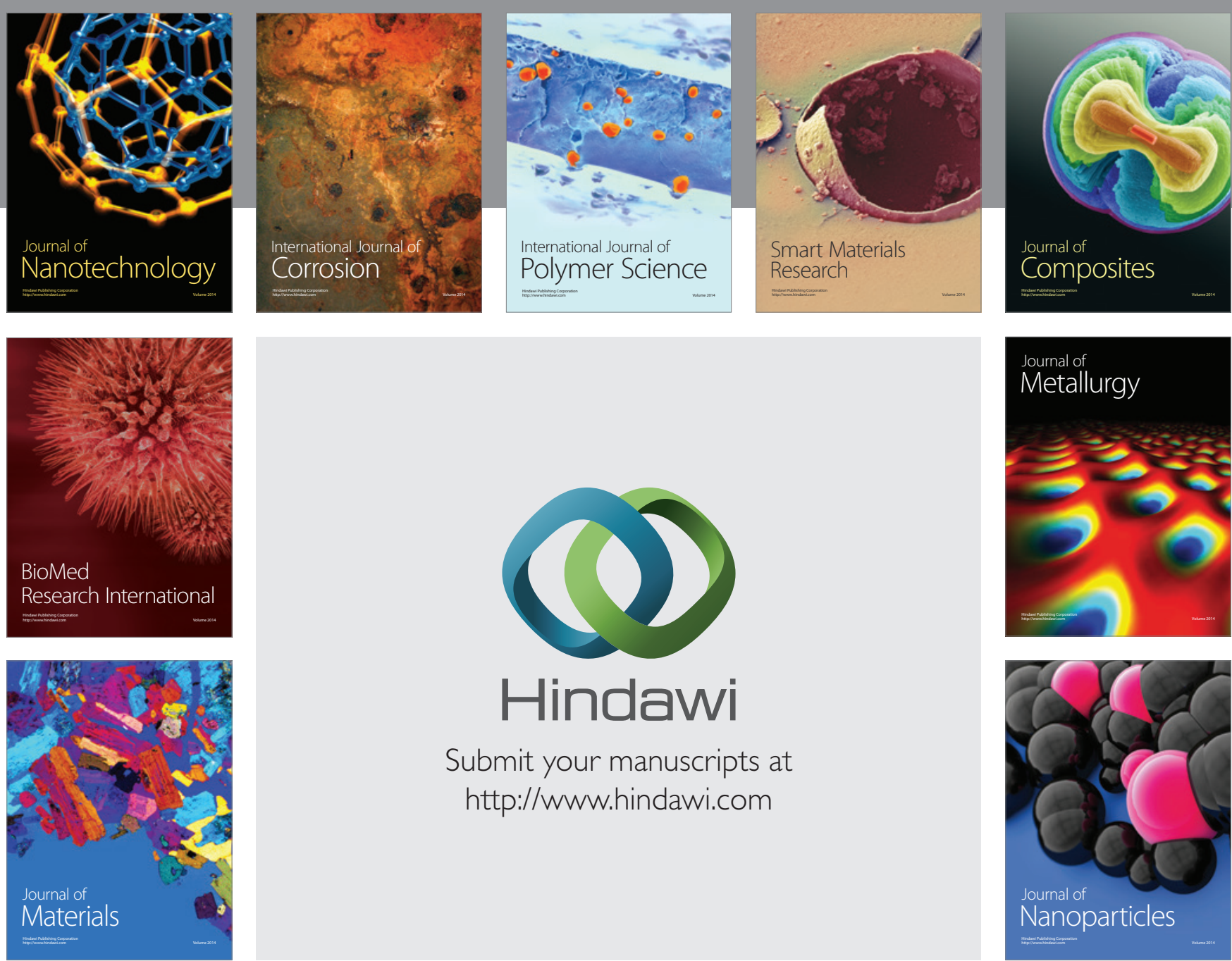

\section{Hindawi}

Submit your manuscripts at

http://www.hindawi.com

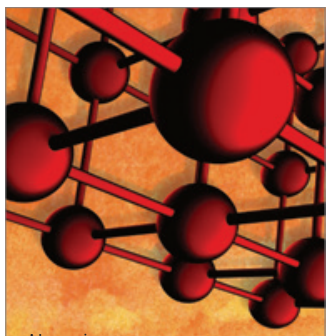

Materials Science and Engineering
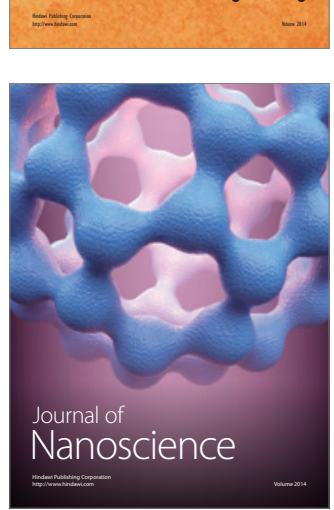
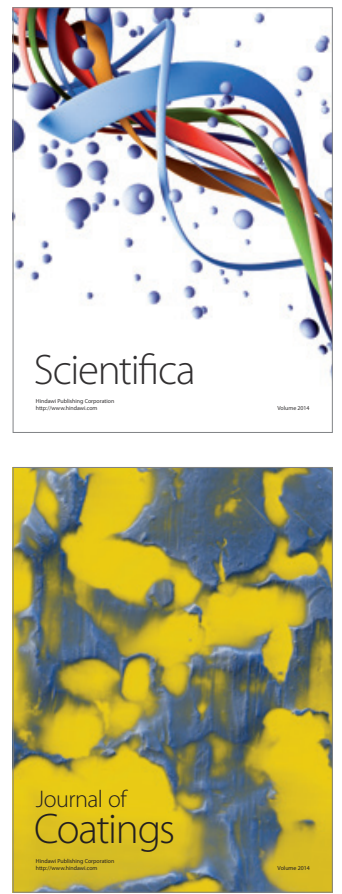
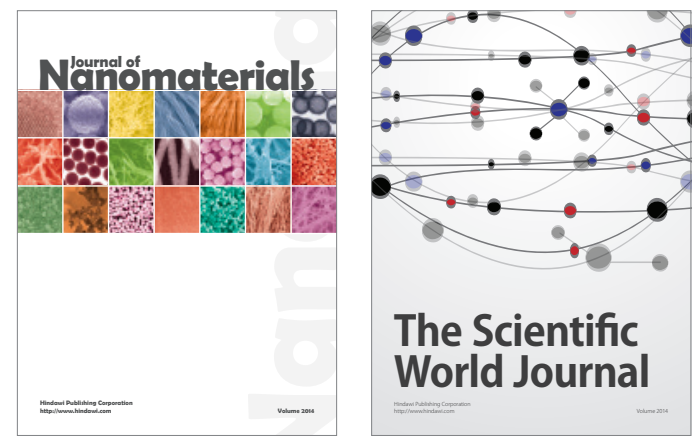

The Scientific World Journal
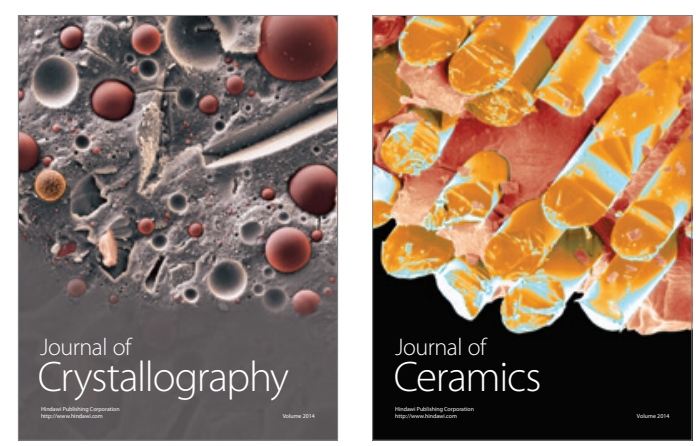
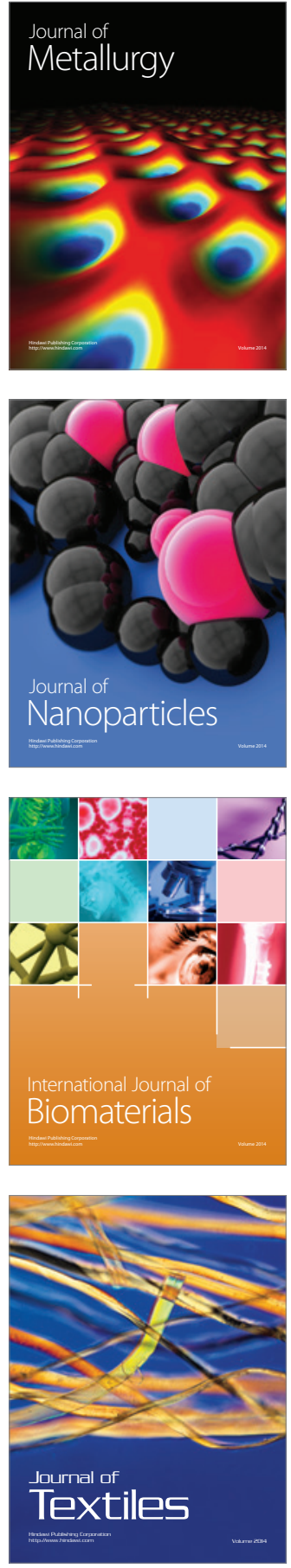